\title{
Web-based GIS by using Spatial Decision Support System (SDSS) Concept for Searching Commercial Marketplace - using Google MAP API
}

\author{
I Nyoman Piarsa \\ Information Technology Dept. \\ Udayana University \\ BALI, INDONESIA
}

\author{
A.A. Kompiang Oka \\ Sudana \\ Information Technology Dept. \\ Udayana University \\ BALI, INDONESIA
}

\author{
Gde Wahyu M. Gunadi \\ Information Technology Dept. \\ Udayana University \\ BALI, INDONESIA
}

\begin{abstract}
Consumers occasionally find difficulty in finding the location of a store or business place they want because there is little information to be found and the information is usually subjective. Web-based GIS technology can be used to search for business place so the consumer can easily find the store or business place they want, along with the address. On the other hand, businesspeople also receive benefit because this system gives the opportunity to promote their businesses. This system was built using concept of web-based geographic information system where there was a map from Google Map API inside the web to make finding the location easier.
\end{abstract}

\section{General Terms}

Spatial Decission Support Concept (SDSS) on Web-based GIS; DBMS with spatial component

\section{Keywords}

Web-based GIS, Google Map Api, marketplace, location, SDSS, searching.

\section{INTRODUCTION}

The advancement in the field of information technology helps business world, whether manufacturer or service, including utilization of spatial data technology. The development of the utilization of spatial data in the past decade has increased drastically. This is related to the increase of the utilization of Geographic Information System (GIS) and the technological development in obtaining, recording, and gathering spatial data. The ability to store becomes bigger, data transfer capacity bigger, and data processing speed faster, making spatial data an inseparable part of the development of information technology. Information or data system based on space is currently one of the most important elements because it functions as the basis of running and supporting various applications. GIS application has also been developed into a website, or also known as Web-based GIS. One of the examples of things made with Web-based GIS, is the making of web-based map by using Spatial Decision Support System (SDSS) concept for company profiles of businesses. Nowadays, consumers occasionally find difficulty finding the location of a store or business place because there is little information to be found and the information is usually subjective. WEBGIS technology can be used to search for business place so the consumer can easily find the store or business place they want, according to the category chosen, along with the address.

\section{WEB-BASED GIS CONCEPT}

GIS is a special information system which manages data with spatial information (with spatial references). Or in a narrower definition, it's a computer system which has the ability to build, store, manage, and display information with geographical reference, i.e. data identified by location, in a database. Practitioners also put people who build and operate it and data as a part of this system. Geographic Information System Technology can be used for scientific investigation, resources management, construction planning, cartography and route planning. For example, GIS can help planner to calculate exact emergency response time during natural disaster, or GIS can be used to look for wetlands which need protection from pollution. The development of GIS application in the future is directed toward Web-based application known as WebGIS. This is because the development of application in network has shown major potential in its relation with geo information. For example an online map of a city where the user can easily find the location they want only thought intranet/internet network regardless of the user's geographic limits. Generally Geographic Information System is developed based on principle of data input, data management, analysis and representation. In web environment, these principles are displayed and implemented on this table:

Table 1. GIS implementation in web development

\begin{tabular}{|l|l|}
\hline GIS Principle & Web Development \\
\hline Data Input & Client \\
\hline Data Management & $\begin{array}{l}\text { DBMS with spatial } \\
\text { component }\end{array}$ \\
\hline Data Analysis & GIS library in the server \\
\hline Data Representation & Client/Server \\
\hline
\end{tabular}

Web server has to be able to communicate with different component in the web. Due to the different and very specific standards of geo data, the development of system architecture followed "Client Server" architecture.

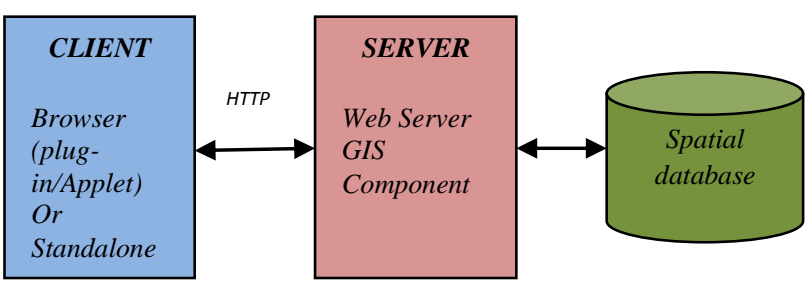




\section{Fig 1: Web-based GIS architecture}

The figure above shows minimum architecture of a WebGIS system. The application is on the side of the client communicating with the server as the data provider through web protocol such as HTTP (Hyper Text Transfer Protocol). To display and interact with GIS data, a browser requires Plug-In or Java Applet or even both. Web Server is responsible for the request process from the client and sends response to the response. In web architecture, a webserver also manages the communication with GIS Component server side. GIS Component server side is responsible for the connection to spatial database such as translating query into SQL and making representation which will be forwarded to the server. In reality GIS Component Server Side in the form of software libraries which offer special service for special analysis on data. Besides component, another equally important this is functional aspect on the client side or in the server. The following figure shows two approaches showing possibilities of functional distribution of client/server system based on pipeline visualization concept $\left[{ }^{6}\right]$.

\section{a. First Approach (Thin Client)}

Focusing on the server side. Almost every process in data analysis is done based on the request on the server side. Data from the processing is sent to the client in HTML format, in which there is a picture file so it can be seen with a browser. In this approach, user interaction is limited and not flexible.

\section{b. Second Approach (Thick / Fat Client)}

Data processing is done on the client side. Data is sent from the server to the client in the form of simplified vector data. Processing and redrawing is done on the client side. This enables the user to interact more interactively and flexibly. A DBMS (Database Management System) is needed to perform geographic data management. Object oriented modeling is very necessary because relational data based modeling can't store spatial data. In spatial analysis, database management system gives a few varieties. There are a few application varieties which can be used as a database, i.e. Oracle Spatial, PostgreSQL, Informix, DB2, Ingres, and, the most popular at the moment, MySQL. $\left[{ }^{6}\right]$ To get analysis functional development on database level, several DBMS have supported programming language procedural. Oracle DBMS offers two possibilities to produce individual operation at database level. The first is PL/SQL, a programming language procedural. The second is Java Virtual Machine (JVM) for Java classes' process at database level.

\subsection{Internet-based GIS in Mapping Business Information}

Utilization of GIS and internet has changed the organizing way through the utilization of geographic information, accessing process, sharing, and data analysis. Therefore, there are many benefits from using GIS and internet online.

User makes a request, with transmission on integrated GIS system. GIS query system in spatial database is done to get map data and making list of marketplace whose location in query area fulfill the demanded category. Each object will be displayed if it has complete company data, such as company name, address, contact, etc. After performing module transformation, convert the characteristics to the representation wanted. Transformation and module integration are integrated in GIS data with data of marketplace, layer identification, and picture representation.

\subsection{Google Map and Google Map API as Online Map Provider Server}

Google map is a free and online virtual globe map service provided by Google, Google map offer map which can be copied and real images of the earth from satellites all around the earth, moon, and also provides travel route system and search of business place in U.S., Canada, Japan, Hong Kong, China, UK, Ireland, and several areas in Europe. Google Maps API is free for commercial use, can be accessed by public and there is no charge for the access. Therefore, the use of Google Map API is very useful in developing interactive map application to help search for business place. Google Map API provides static map to then be processed into interactive map similar with search engine, complete with search criteria for business(Wikipedia).

\subsection{SDSS Characteristic, Component and Implementation}

The term SDSS is frequently used to describe DSS applications with a simple mapping component, where little or no GIS technology is used. Conversely, other GIS applications could be characterised as SDSS, although the system builders do not describe them as such. In assessing the role of GIS in decision support, it is useful to look at the exact capabilities of these systems. Modern GIS software comprises a spatial database for the storage of spatially indexed data. It contains a visual interface for the display of this data in the form of maps and this interface can be used to initiate spatial database operations. Consequently, the GIS interface serves as both report generator and a conduit for specifying user information requirements. This dual role complicates the design of GIS interfaces and makes these systems relatively complex to use. Consequently, GIS applications can especially benefit from better designed human-computer interfaces which meet their specific needs $\left[{ }^{5}\right]$. On SDSS component, we identify four core components and one optional component. Core components of SDSS include (1) the database management component (DBMC), (2) the model management component (MMC), (3) the dialog management component (DMC), and (4) the stakeholder component (SC) (Figure 2). The knowledge component (KC) is a common but not essential component in an SDSS. Figure 2 provides an overview of the components in an SDSS.

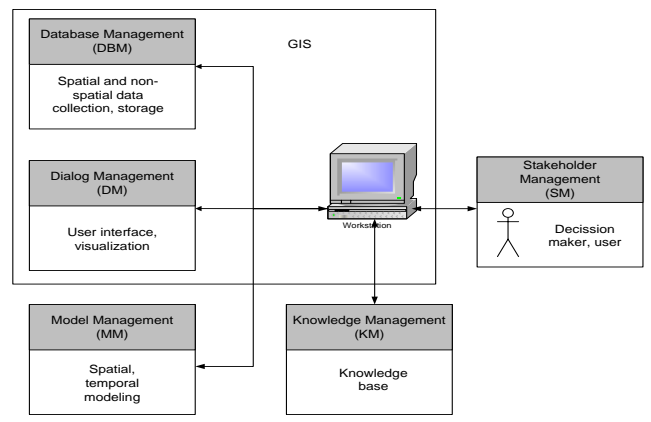

Fig 2: Component of SDSS

Our research into the SDSS literature, demonstrated that the great majority of SDSS had GIS as the key software in database management and dialog management functions $\left[^{1}\right]$. 
The data required in spatial systems is typically a combination of general data on the geography of regions and specific data related to the area of decision-making. The general data is typically outsourced outside the organisation using it; this is less common in the general DSS field. The user of the SDSS is operating at the decision level of problem, for example trying to improve customer service or make the logistics function more efficient. The end user of an SDSS is not directly concerned with spatial techniques $\left[{ }^{2}\right]$.

\section{OVERVIEW WEB-BASED GIS SDSS USING GOOGLE MAP API}

Google Maps offers an API that allows developers embed Google Maps in their own web pages. There is growing interest in the concept of online GIServices, which allow users access data sets from remote geodata repositories $\left.{ }^{3}\right]$. SDSS applications typically involve the use of a large data set to produce a much smaller set of output, a scenario well suited to a client/server model $\left[{ }^{4}\right]$. Google map api is commonly used in the manufacture of interactive maps. Along with the mapping development, by using the concept of SDSS, spatial data such as latitude and longitude coordinates can be combined with regular data such as category and location, so it can be made a decision support, shown in the following (Fig4).

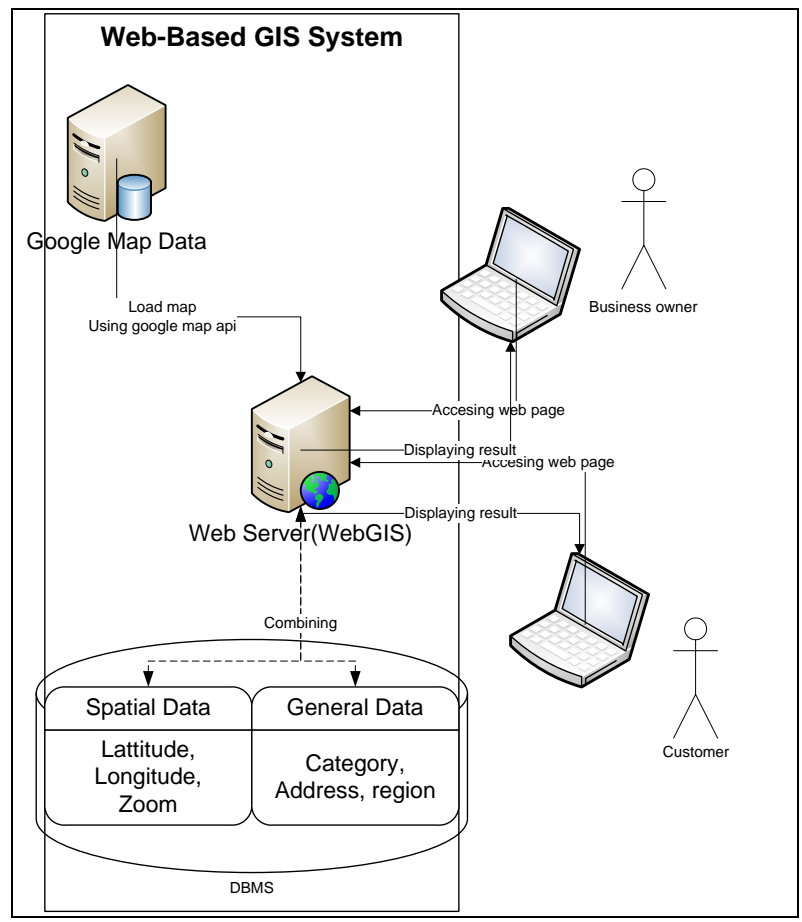

Fig 4: Overview the System

Now, on this system, business owner applies his business to WebGIS. WebGIS administrators will manually verify the documents or business license. Next, the customer or society search for a certain business, i.e. clothing store in the capital. WebGIS will respond by displaying clothing stores with the highest popularity to the stores with the lowest popularity in the map. Sequence of the businesses on the list uses Spatial Decision Support System (SDSS) concept. The system will list business with the most comment to the least. The website also provides a place to give rating to each business. The system will also monitor the businesses regularly for 3 months. If re-registration is not done, the business's status will be declared inactive. This is done to provide fact of the business's existence to the customers.

\subsection{Entity Relationship Diagram (ERD) of Web-based GIS System For Searching Comercial Marketplace}

Entities involved are:

a. Business Owner

Business owner is one of the main entities needed in designing database. According to the procedure, to display, edit, and delete his company's profile, business owner must login to register to the provided area.

b. WebGIS (as the system)

WebGIS is one of the important entities in making database design, where the entity acts directly as the system or administrator which deals with the interaction between business owner and business seeker or customer.

\section{c. Customer}

Customer is one of the main entities in Web-based GIS business database design, in which the entity has the role as business seeker as well as end user. To be a customer, there is no need to register, but the authority is limited (only able to perform search for business, but unable to comment or vote). To comment or vote, the customer must login first. Business owner, webgis, and customer entity's relationships and attributes can be connected, as shown in the following (Fig 3):

\subsection{Relationship Between Tables}

After determining ERD and its relations, next is deciding table design (normalized) or the relation between the tables with the following explanations:

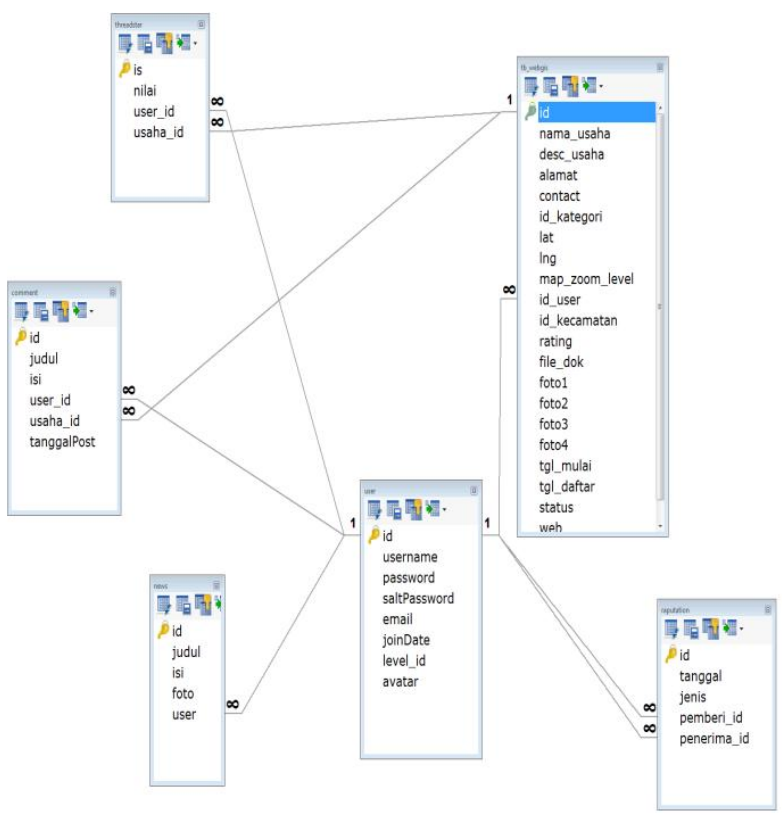

Fig 5: Relationship Between Tables 


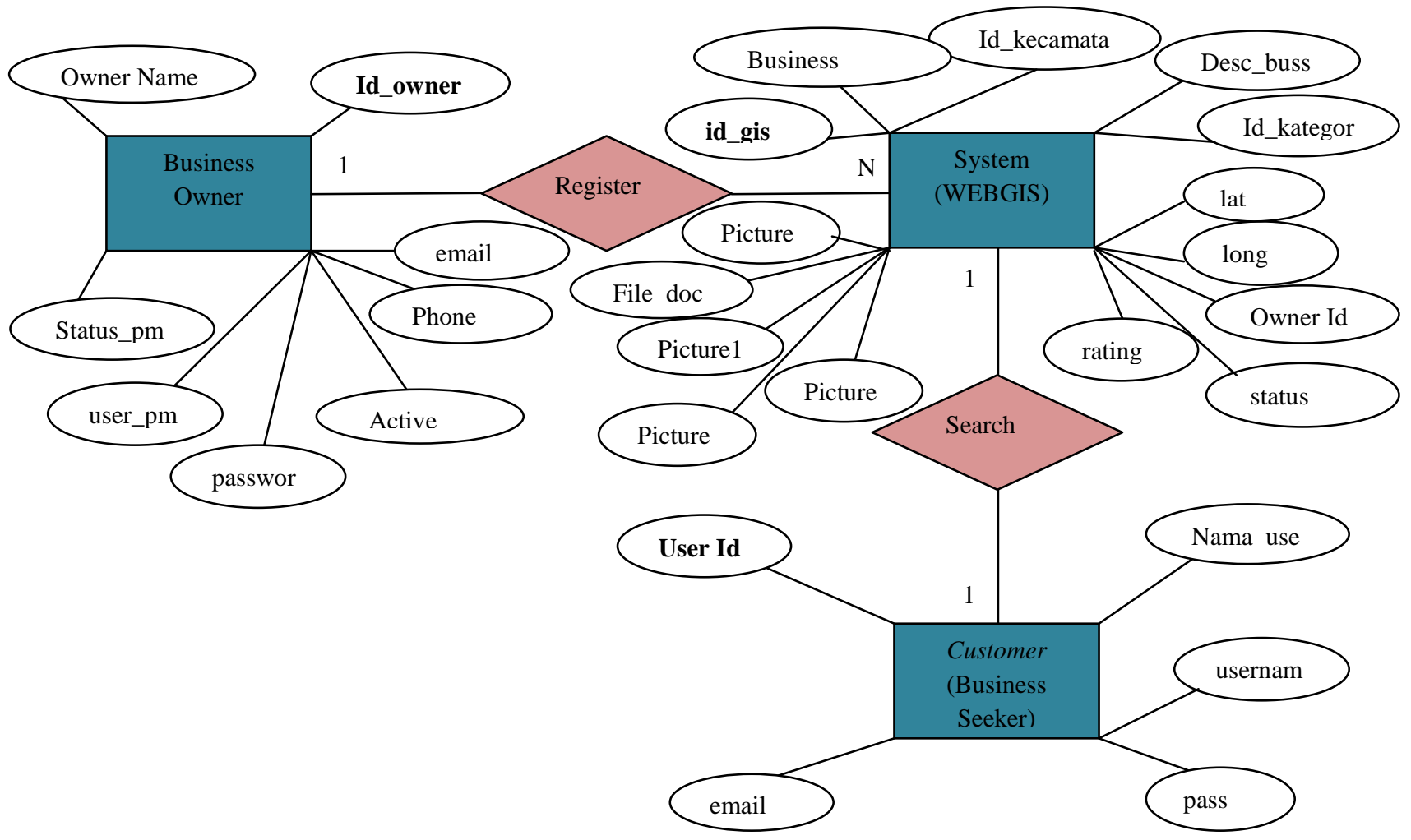

Fig 3: Entity Relationship Diagram

\section{USER INTERFACE DESIGN}

Web-based GIS application for searching commercial marketplace which will be made using a simple but weighty appearance.

\subsection{Application Structure}

The application structure of this system shown on the following (Fig 7):

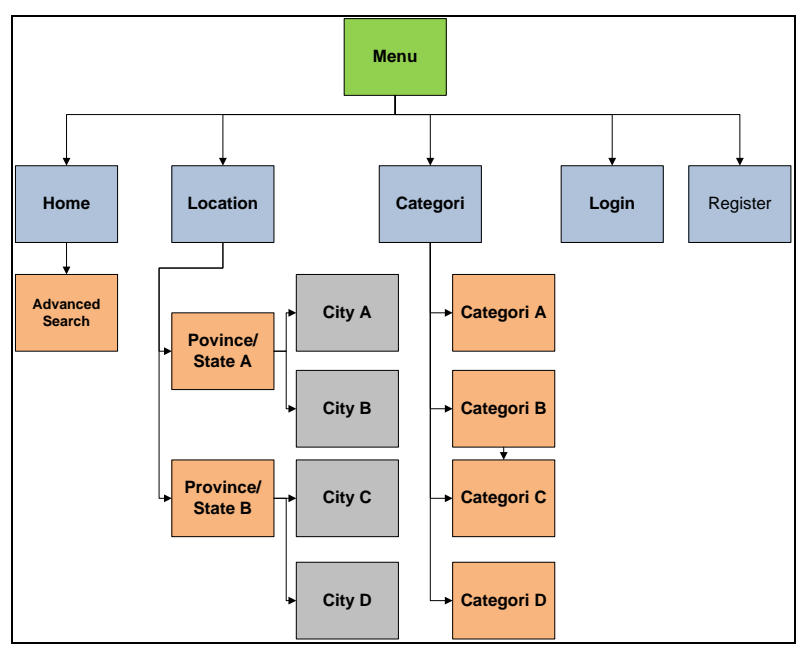

Fig 7: Application Structure

According to application structure (Fig 7), if implemented, it can be made a web-based GIS as the following:

a. Create a new business or marketplace (for business owner)

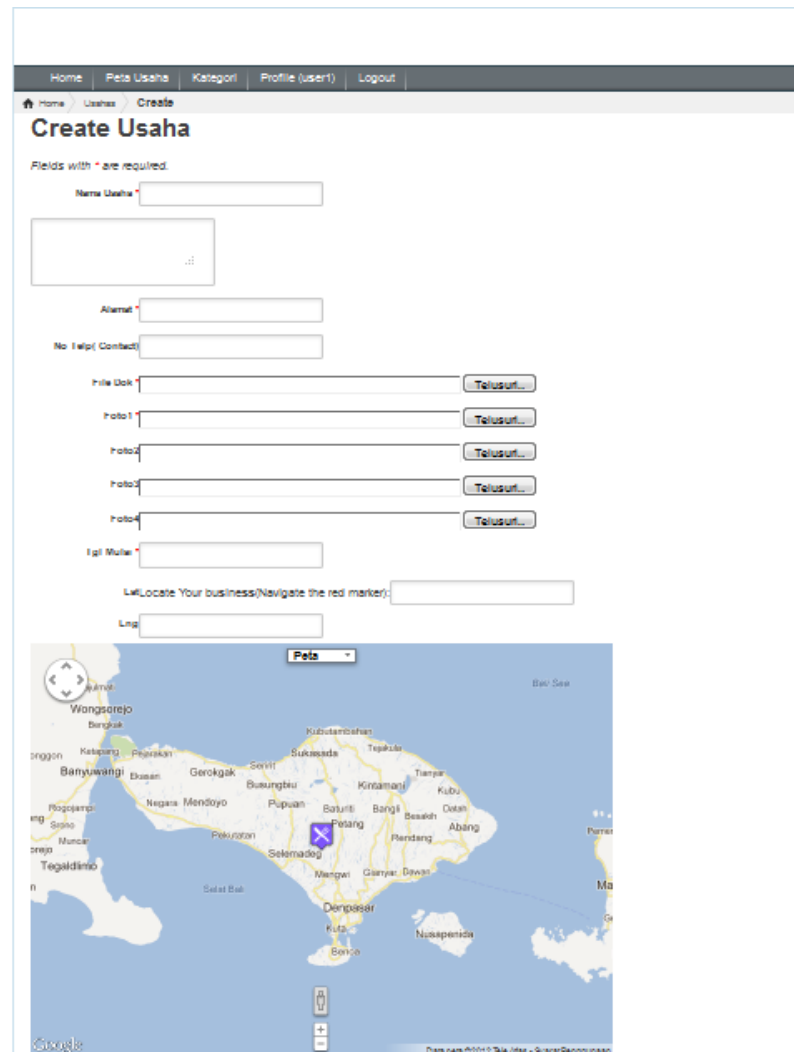

Fig 8: Web-based GIS Application in Create New Comercial Marketplace

To create a new business (Fig 8), the system requires a member(business owner) to enter data that will be useful in helping the decision making process in the search such as : 
company name, address, short description of company profile, contact phone (hotline), category of company, establishment date of business, business license, profile picture of company, lattitude and longitude (can be dragged from marker).

b. View and searching marketplace or business place (for customer)

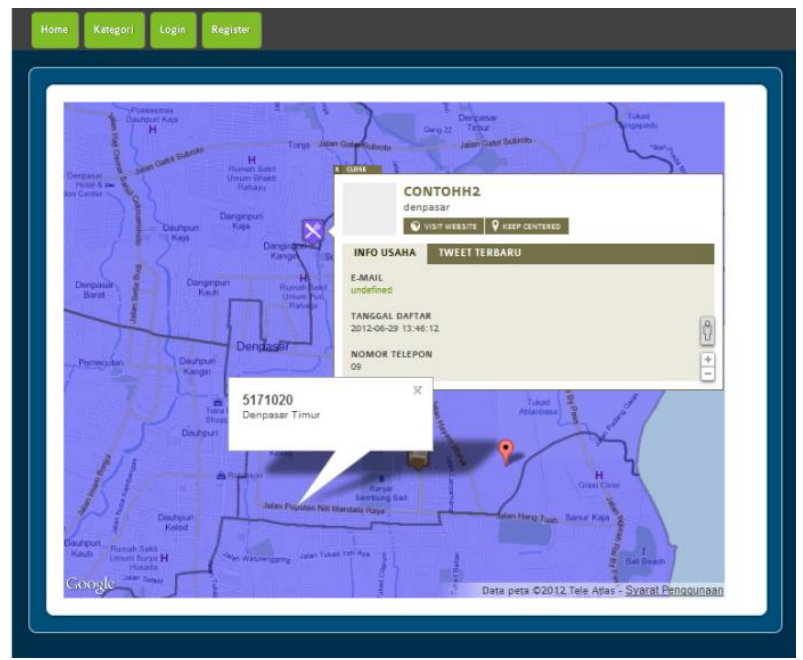

Fig 9: Web-based GIS Application in Searching Comercial Marketplace

Businesses that have registered will be entered into the database, these data will be used in the spatial decision support-making process. When doing a search, visitors are required to determine the categories and region where the business is to search. By using the kml file, the mapping is much easier because $\mathrm{kml}$ can map an area making it easier for users to find a region of business place. For example, if a customer or a visitor wants to find a market in a village, so visitors should choose the area where the village and the market categories in the category menu. Next, the system will perform the data query categories and areas of the businesses. The results of this query would be more than one (see fig 9) and the result is to be considered when making decisions in the search marketplace. In addition, visitors may comment on a business or marketplace (see fig 10)

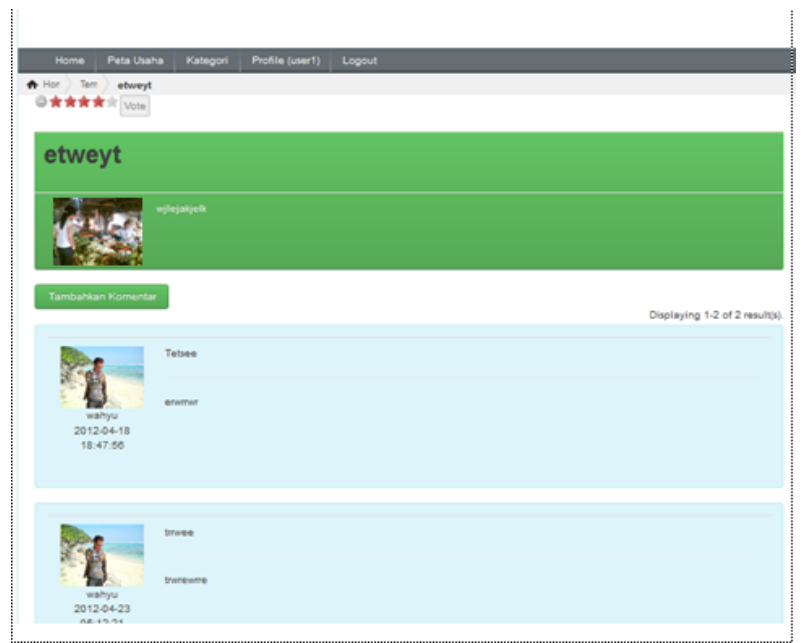

Fig 10: User Comments
These comments will also affect the determination of top company, this will certainly affect the determination of spatial-based decisions support. More comments in a marketplace it will be more up the rankings so that more visitors will see the business (see fig 11) $\left[^{7}\right]$.

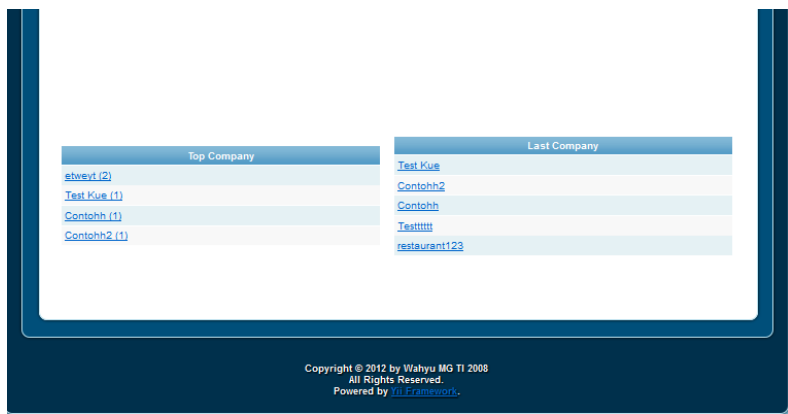

Fig 11: Top Company

\section{CONCLUSION}

SDSS concept can be applied to the Web-based GIS, especially for search business or comercial marketplace. By combining the spatial data such as latitude, longitude, region and general data such as categori, address, comment, company name, etc. It will be able to set up a spatial decision support based on a variety of benefits such as: increasing the popularity of a business, helps visitors determine the business or the marketplace that he liked.

\section{REFERENCES}

[1] Sugumaran, R., DeGroote, John. 2011. Spatial Decission Support System Principles and Practice. CRC Press.

[2] Keenan, Peter B. 2006. Spatial Decission Support System : A Coming of Age. Forthcoming in Control and Cybernetics Journal.

[3] Tao, C. V. 2001. Online GIServices. Journal of Geospatial Engineering, 3(2), 135-143.

[4] Coddington, P. D., Hawick, K. A., \& James, H. A. 1999. Web-Based Access to Distributed HighPerformance Geographic Information Systems for Decision Support. Paper presented at the 32nd Hawaii [1] International Conference on System Sciences, Maui, Hawaii, USA.

[5] Hearnshaw, H., \& Medyckyj-Scott, D. (1993). The way forward for human factors in GIS. In D. MedyckyjScott \& H. Hearnshaw (Eds.), Human factors in Geographical Information Systems (pp. 235-243). London: Belhaven Press.

[6] Charter, Denny. 2004. Desain dan Applikasi GIS, PT. Elex Media Komputindo, Jakarta.

[7] Huraira, S. 2012. Menjelajah Yii. Jakarta. 